\title{
Opposite actions of dopamine on aversive and appetitive memories in the crab
}

\author{
Martín Klappenbach, ${ }^{1,4}$ Héctor Maldonado, ${ }^{1,2}$ Fernando Locatelli, ${ }^{1,3}$ and \\ Laura Kaczer ${ }^{1,3}$ \\ ${ }^{1}$ Laboratorio de Neurobiología de la Memoria, Departamento de Fisiología y Biología Molecular y Celular, IFIBYNE-CONICET, \\ Pabellón II, Facultad de Ciencias Exactas y Naturales, Universidad de Buenos Aires, Buenos Aires C1428EGA, Argentina
}

\begin{abstract}
The understanding of how the reinforcement is represented in the central nervous system during memory formation is a current issue in neurobiology. Several studies in insects provide evidence of the instructive role of biogenic amines during the learning and memory process. In insects it was widely accepted that dopamine (DA) mediates aversive reinforcements. However, the idea of DA being exclusively involved in aversive memory has been challenged in recent studies. Here, we study the involvement of DA during aversive and appetitive memories in the crab Chasmagnathus. We found that DA-receptor antagonists impair aversive memory consolidation, in agreement with previous reports in insects, while administration of DA facilitates memory formation after a weak training protocol. In contrast, DA treatment during appetitive training was found to impair formation of long-term appetitive memory. In addition, as a first step in elucidating the neuroanatomical correlates of DA action on memory, we mapped dopaminergic neurons in the central nervous system of the crab. Results of the current study, together with those obtained in a previous work about the role of octopamine (OA), suggest that both amines (DA and OA) play a dual action in memory processes. On the one hand, DA and OA mediate the aversive and the appetitive signals, respectively, throughout training, while on the other hand, they interfere with the formation of memory of the opposite sign (DA in appetitive and OA in aversive). Our results support a new understanding about the way appetitive and aversive stimuli are processed during memory formation to ensure adaptive behavior.
\end{abstract}

An intriguing issue in the study of associative learning is to determine which neurochemical mechanisms underlie memory representations in the brain. Invertebrate models are particularly useful for tackling this question at the behavioral, cellular, and molecular levels (Heisenberg 2003; Giurfa 2006; Menzel et al. 2006). In this sense, recent studies in insects have shown that two monoamines, dopamine (DA) and octopamine (OA), can substitute, respectively, for the aversive and appetitive reinforcements used in conditioning (Schwaerzel et al. 2003; Schroll et al. 2006; Unoki et al. 2006; Vergoz et al. 2007). In Drosophila it was demonstrated that transgenic flies defective in DA or OA synthesis exhibited defects in aversive learning with electric shock or appetitive learning with sucrose reward, respectively (Schwaerzel et al. 2003). Subsequent studies in fruit flies confirmed that dopaminergic neurons indicate electric-shock punishment during aversive olfactory conditioning in larvae (Schroll et al. 2006; Honjo and Furukubo-Tokunaga 2009; Selcho et al. 2009) as well as in adult flies (Riemensperger et al. 2005; Claridge-Chang et al. 2009; Tomchik and Davis 2009; Aso et al. 2010), while octopaminergic neurons convey signals for sucrose reward (Schwaerzel et al. 2003; Schroll et al. 2006). Furthermore, the roles of DA and OA in conveying aversive or appetitive reinforcement signaling have also been demonstrated in honeybees' olfactory and gustatory conditioning (Hammer and Menzel 1998; Farooqui et al. 2003; Vergoz et al. 2007; Wright et al. 2010) and in crickets'

2In memoriam (1927-2010).

${ }^{3}$ These authors contributed equally to this work.

${ }^{4}$ Corresponding author.

E-mail martinklappenbach@hotmail.com.

Article is online at http://www.learnmem.org/cgi/doi/10.1101/lm.024430.111. olfactory and visual conditioning (Unoki et al. 2005, 2006). With few exceptions (Kim et al. 2007; Selcho et al. 2009), these studies suggest separate mechanisms for aversive and appetitive processing, supported by DA and OA, respectively.

However, the idea of each amine being exclusively involved in one type of memory was challenged by a study in our laboratory, performed on the crab Chasmagnathus (Kaczer and Maldonado 2009). It was demonstrated that $\mathrm{OA}$ is necessary for appetitive memory formation, in coincidence with the above findings in insects, but, remarkably, OA was also found to impair aversive memory consolidation. In addition, OA revealed an inhibitory action on the reconsolidation phase of aversive memory (Kaczer et al. 2011). These results unraveled a novel process of action for a biogenic amine in learning, showing that it acts with divergent roles in two memory processes of opposite signs. The same finding was recently confirmed in honey bees (Agarwal et al. 2011), suggesting that the postulated dual action of OA is conserved across species. An interesting question is whether or not such dual function could be extended to DA, the putative punishment mediator.

To address this question, we made use of a well-characterized model for the study of aversive and appetitive memory, the crab Chasmagnathus granulatus (Maldonado 2002). The aversive learning paradigm is based on the crab's escape response elicited by the presentation of a visual danger stimulus (VDS). Upon iterative presentation of the VDS, a decline in escape response is observed. This decline persists at least $5 \mathrm{~d}$ (Pereyra et al. 2000), and it has been shown to result from an association between the training context and the VDS, since a training-to-test context shift abolishes memory retrieval (Tomsic et al. 1998; Hermitte et al. 1999). Additional convincing arguments about the associative 
nature of this learning and memory paradigm were obtained from studies performed to examine memory reconsolidation in this model. Those experiments showed that the mere re-exposure of the crab to the learning context provokes a labilization of the reactivated memory (e.g., Pedreira et al. 2002, 2004; Pedreira and Maldonado 2003). This result is consistent with the idea that the context becomes a predictor of the VDS presentation. Concerning appetitive learning, food is used as a positive reinforcement, which becomes associated with the context where it was received. The outcome of this learning protocol is a longlasting memory, expressed by an increase in exploratory activity when the crab is reinstalled in the same context (Kaczer and Maldonado 2009). In order to make comparisons between aversive and appetitive memories more feasible, we used the same training context in both learning paradigms.

In the present work we analyzed the involvement of DA in aversive and appetitive memories in the crab Chasmagnathus. Furthermore, we made the first description of dopaminergic pathways in the central brain of this species.

\section{Results}

\section{DA-receptor antagonists impair consolidation but not acquisition of an aversive memory}

We first aimed to analyze the role of DA in an aversive memory paradigm. Thus, we performed a series of experiments evaluating the effect of three DA-receptor antagonists whose effectiveness has been previously reported for other invertebrates: chlorpromazine (Mustard et al. 2003), fluphenazine (Degen et al. 2000), and SCH23390 (Blenau et al. 1998). We performed three different experiments, each containing two pairs of U-T groups, in which the $\mathrm{T}$ groups were given a series of 15 VDS trials, while the $\mathrm{U}$ groups remained in the experimental arena without VDS presentation. In all cases, a saline-injected pair was included (SAL pair), and the other pair received an injection of a DA-receptor antagonist, chlorpromazine $1 \mathrm{mM}$ (CPZ pair), fluphenazine $1 \mathrm{mM}$ (FLU pair), or SCH23390 $1 \mathrm{mM}$ (SCH pair). Injections were applied $30 \mathrm{~min}$ before training. Results of the testing session are shown in Figure 1. Planned comparisons revealed a significant difference between the U-SAL and T-SAL groups in the three experiments (CPZ experiment: $F_{(1,70)}=9.68, P<0.01$; FLU experiment: $F_{(1,81)}=7.57, P<0.01$; SCH experiment: $F_{(1,87)}=$ $7.50, P<0.01)$. The observed differences correspond to the longterm memory retention normally expected after a strong training protocol. On the other hand, no differences were disclosed between U-T groups in the CPZ pair $\left(F_{(1,70)}=0.05, P=0.83\right)$, the FLU pair $\left(F_{(1,81)}=0.93, P=0.34\right)$, or the SCH23390 pair $\left(F_{(1,87)}=1.35, P=0.25\right)$. From these, we conclude that DA-receptor antagonists impair aversive memory retention at $24 \mathrm{~h}$, suggesting that DA signaling may be involved in aversive memory formation.

Considering the above findings, it is important to discern whether DA-receptor antagonists impair the acquisition or the consolidation of aversive memory. To solve this issue, we analyzed the animals' responses during the training session, performed 30 min after drug injection (Fig. 2). Statistical analysis based on a two-way ANOVA with repeated measures (trials) showed no significant differences between T-SAL and either T-CPZ, T-FLU, or T-SCH groups (CPZ experiment: $F_{(1,36)}=0.56, P=0.46 ; \mathrm{SCH}$ experiment: $F_{(1,45)}=0.04, P=0.84$; FLU experiment: $F_{(1,48)}=$ $0.71, P=0.40)$, a significant effect of trials for all groups (CPZ experiment: $F_{(4,144)}=49.08, P<0.001$; SCH experiment: $F_{(4,180)}=38.13, P<0.001$; FLU experiment: $F_{(4,192)}=43.32, P<$ $0.001)$, and no significant interaction between factors (CPZ experiment: $F_{(4,144)}=0.08, P=0.54$; SCH experiment: $F_{(4,180)}=$ 1.06, $P=0.38$; FLU experiment: $F_{(4,192)}=0.82, P=0.52$ ). Thus, at least for these concentrations, the drugs proved not to affect the animals' responsiveness during training. These results indicate that the memory deficit is due to an interference of the DA-receptor antagonists with the memory consolidation phase. Moreover, the fact that these drugs do not influence the naive escape response (first training trial, Fig. 2) rules out the possibility of an effect of the drugs on perception of the VDS or escape motor patterns.

The purpose of the following series of experiments (Fig. 3) was to define the time window during which DA receptors are critical for aversive memory formation. We used one of the
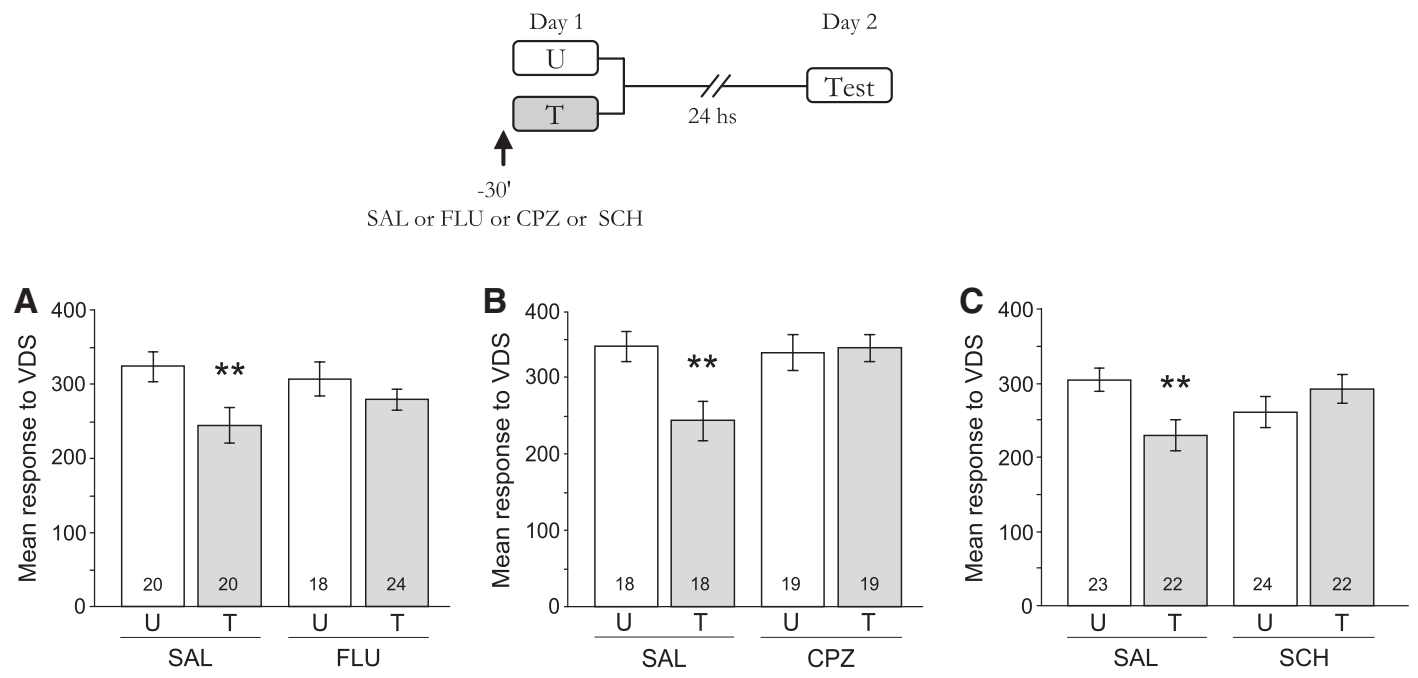

Figure 1. DA-receptor antagonists impair long-term aversive memory. (Top) Experimental design. Training session: White boxes stand for $\mathrm{U}$ groups and gray boxes for T groups, which received 15 VDS presentations. Systemic injections into the pericardial sac were performed 30 min before training session (arrow). Testing session was performed $24 \mathrm{~h}$ later. (Bottom) Escape response at testing session. Mean response to VDS \pm S.E.M. White bars indicate untrained groups and gray bars indicate trained groups. Number of animals indicated for each bar. Animals were injected with saline or fluphenazine $(A)$, saline or chlorpromazine $(B)$, saline or SCH $23390(C) .\left(^{* *}\right) P<0.01$. 

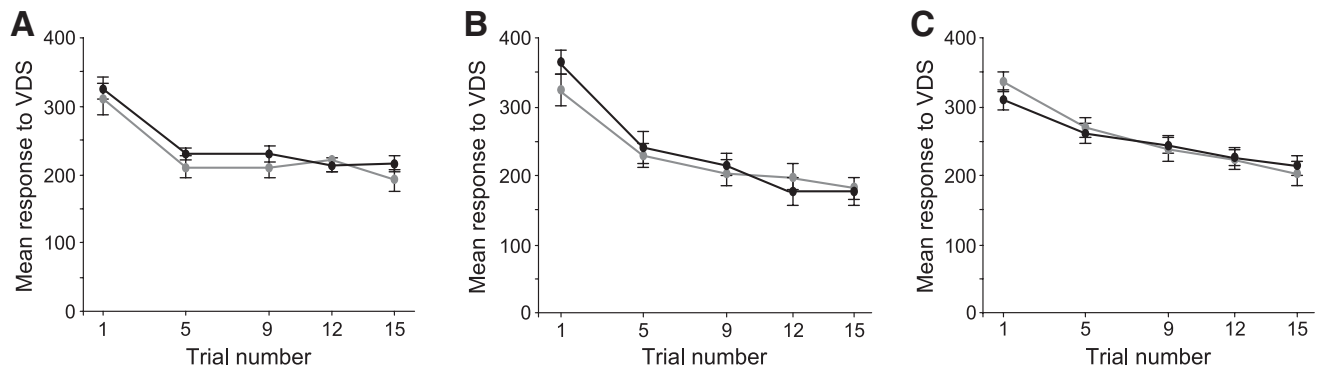

Figure 2. DA receptor antagonists do not affect acquisition. Mean response to VDS \pm S.E.M during the training session. $(A)$ Gray circles stand for SAL $(n=20)$ and black circles for fluphenazine $(n=24)$-injected T groups. $(B)$ Gray circles stand for SAL $(n=18)$ and black circles for chlorpromazine $(n=$ 19)-injected T groups. (C) Gray circles stand for SAL $(n=22)$ and black circles for SCH23390 $(n=22)$-injected T groups.

DA-receptor antagonists tested in the previous section (chlorpromazine) and injected it at different times with respect to training. Injections were performed 45,30 , or 15 min before the beginning of training session $(-45,-30$, and $-15 \mathrm{~min}$, respectively) or $60 \mathrm{~min}$ after its end (+60 min). In all cases, the experimental protocol included two U-T pairs: one pair was injected with saline solution (SAL pair) and the other with $1 \mathrm{mM}$ chlorpromazine (CPZ pair). Statistical analysis of testing session (Table 1) indicates an impairing effect of chlorpromazine only when it was applied $30 \mathrm{~min}$ before training. No deleterious effect was disclosed for injections at 45 or $15 \mathrm{~min}$ before training or for the post-training administration. In conclusion, the amnesic effect of chlorpromazine is restricted to an early stage of aversive memory formation during training.

In the experiments reported above, we concluded that DA-receptor antagonists do not impair learning, as is shown from the unaffected performance during training. However, the same antagonists prevent memory retention $24 \mathrm{~h}$ after training. These results suggest a short lasting memory responsible for the decrease in escape response during training, which is not affected by DAreceptor antagonists, and a late memory trace that requires DA signaling during training. In the next experiment we asked when the DA-dependent memory emerges after training. Two pairs of $\mathrm{U}-\mathrm{T}$ groups were used: a SAL pair (injected with saline solution) and a CPZ pair (injected with chlorpromazine $1 \mathrm{mM}$ ), injected $30 \mathrm{~min}$ before training. The testing session was carried out $3 \mathrm{~h}$ after the end of training (Fig. 4). Planned comparisons revealed a significant $\mathrm{U}-\mathrm{T}$ difference in SAL pair $\left(F_{(1,89)}=7.46, P<0.01\right)$, but not in the CPZ pair $\left(F_{(1,89)}=0.01, P=\right.$ $0.94)$. Thus, memory is already impaired by chlorpromazine $3 \mathrm{~h}$ after training.

\section{DA facilitates a weak aversive memory}

In the previous section it was demonstrated that the inhibition of endogenous DA produces memory impairment. Here, we use a complementary analysis in order to evaluate the role of DA in $\left({ }^{* *}\right) P<0.01,(* * *) P<0.001$. aversive memory formation. We addressed whether it is possible to enhance a weak aversive memory by increasing DA internal levels. Thus, in the following experiment we used a weak training protocol, in which $\mathrm{T}$ groups received five training trials that are insufficient to generate long-term memory (Delorenzi et al. 2000) and analyzed a possible facilitatory effect of DA. Two pairs of U-T groups were included: a saline-injected pair (SAL pair) and a DA $0.1 \mathrm{mM}$-injected pair (DA pair). Results corresponding to the testing session (performed $24 \mathrm{~h}$ after training) are shown in Figure 5. Planned comparisons show no difference between $\mathrm{U}-\mathrm{T}$ groups of the SAL pair $\left(F_{(1,75)}=0.44, P=0.51\right)$, as expected from the use of a weak training protocol, whereas a significant
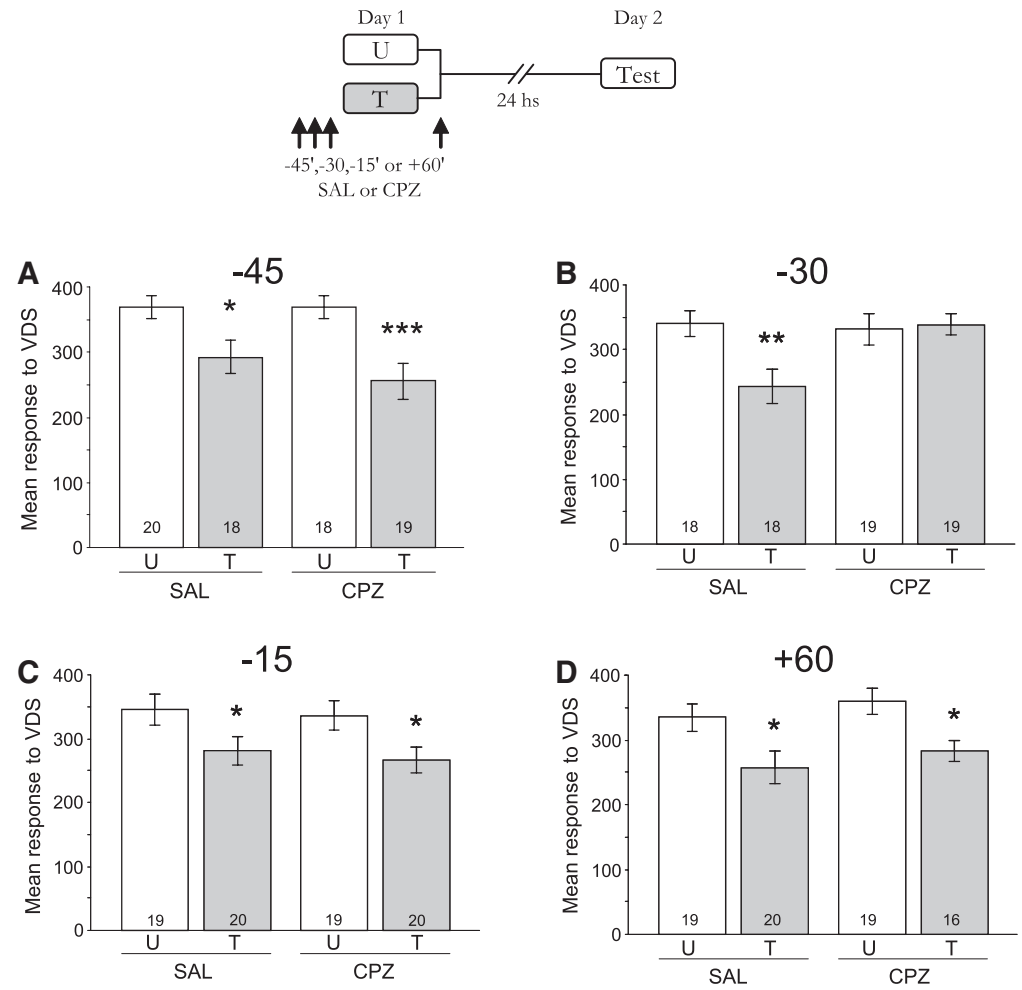

Figure 3. Dopamine has a limited time window of action on aversive memory formation. (Top) Experimental protocol. SAL or $1 \mathrm{mM} \mathrm{CPZ} \mathrm{were} \mathrm{systemically} \mathrm{injected}-45,-30$, or -15 min (pretraining), or $60 \mathrm{~min}$ after training. (Symbols as in Figure 1.) (Bottom) Escape response at testing session. Ordinates and symbols as in Figure 1. Animals were injected $45 \mathrm{~min}$ before training session $(A), 30 \mathrm{~min}$ before training session $(B), 15$ min before training $(C)$, or $60 \mathrm{~min}$ after training $(D)$. $\left(^{*}\right) P<0.05$, 
Table 1. Statistics corresponding to the experiments displayed in Figure 3

\begin{tabular}{lll}
\hline Time of injection & U-SAL vs. T-SAL & U-CPZ vs. T-CPZ \\
\hline-45 min & $F_{(1,71)}=5.746$ & $F_{(1,70)}=12.456$ \\
-30 min & $P<0.05$ & $P<0.01$ \\
& $F_{(1,70)}=4.677$ & $F_{(1,70)}=0.047$ \\
-15 min & $P<0.01$ & $P=0.829$ \\
& $F_{(1,74)}=4.055$ & $F_{(1,74)}=4.659$ \\
60 min & $P<0.05$ & $P<0.05$ \\
& $F_{(1,69)}=6.852$ & $F_{(1,69)}=5.648$ \\
& $P<0.05$ & $P<0.01$ \\
\hline
\end{tabular}

difference $\left(F_{(1,75)}=5.31, P<0.05\right)$ is found in the DA-injected pair. Thus, this result reveals that, by increasing DA levels during training, it is possible to facilitate aversive memory formation, mimicking the effects of a strong training protocol.

Next, we asked whether the facilitatory effect of DA on aversive memory is due to the action on its specific receptors. If that is the case, we may prevent this effect by coinjecting DA with a DA-receptor antagonist. Thus, we performed an experiment including three U-T pairs: a saline-injected one (SAL pair), a DA $100 \mu \mathrm{M}$-injected pair (DA pair), and a pair injected with a cocktail of DA $0.1 \mathrm{mM}$ + fluphenazine $0.1 \mathrm{mM}$ (FLU + DA pair). Note that the concentration of fluphenazine used in this experiment is 10 times lower than the concentration previously used to induce amnesia after a strong training protocol. The results are shown in Figure 6A. Planned comparisons showed no U-T differences in the SAL pair $\left(F_{(1,127)}=0.99, P=0.32\right)$ and the DA + FLU pair $\left(F_{(1,127)}=0.05, \quad P=0.83\right)$, whereas a significant difference $\left(F_{(1,127)}=7.54, P<0.01\right)$ is found in the DA-injected pair. Thus, the facilitatory effect of DA can be blocked when the amine is coadministered with its antagonist.

In addition, we analyzed the animal's responses during training to evaluate whether DA improved memory acquisition. Statistical analysis (two-way ANOVA with repeated measures) showed no significant differences between T-SAL and either T-FLU or T-FLU + DA groups $\left(F_{(2,66)}=0.75 ; P=0.48\right)$, significant differences among trials $\left(F_{(2,132)}=38.18 ; P<0.001\right)$, and no significant interaction between factors $\left(F_{(4,132)}=0.82 ; P=0.51\right)$ (Figure 6B). We conclude from these results that DA does not modify the animals' performances during training. Thus, the facilitatory effect of DA occurs during an early phase of memory formation, via the action on its specific receptors.

Briefly, we have demonstrated that DA is required for the consolidation of an aversive memory, but not for its acquisition. In addition, the amnesic effect of DA-receptor antagonists occurs within a very narrow time window ( $-30 \mathrm{~min}$ ) and emerges at least $3 \mathrm{~h}$ after training session. Finally, we found that by increasing DA levels it is possible to enhance aversive memory after a weak training protocol.

\section{DA interferes with appetitive memory formation}

In the following series of experiments we analyzed whether DA plays any role in the appetitive memory paradigm in crabs. Firstly, we carried out an experiment to address whether DA affects appetitive memory formation. The appetitive training procedure and the evaluation of appetitive memory were performed according to Kaczer and Maldonado (2009). During the training session, T groups were placed in the training context and received food after 5 min of exploration, whereas U groups remained in the training context without food throughout the whole session. Two pairs of U-T groups were used: a SAL pair, injected with saline solution, and a DA pair, injected with $0.1 \mathrm{mM}$ DA. Based on the results obtained in the aversive paradigm, all injections were administrated 30 min before the beginning of a training session. Importantly, we measured the exploratory activity displayed before food was delivered into the training context. No difference was observed between SAL- and DA-injected animals, indicating that the crabs' exploratory activity was not influenced by DA during training (data not shown). After finishing the training session, we confirmed that both trained groups completely consumed the food pellet provided as US. The testing session was performed $48 \mathrm{~h}$ after training, i.e., $48.5 \mathrm{~h}$ after DA injection. This 2-d interval between training and testing allow us to clearly separate the time of injection from the time of retrieval. Also, it has been previously shown that after $2 \mathrm{~d}$, this memory is well consolidated. Results of exploratory behavior during the testing session are shown in Figure 7A. Planned comparisons revealed a significant difference between $\mathrm{U}-\mathrm{T}$ groups $(\mathrm{T}>\mathrm{U})$ of the SAL pair $\left(F_{(3,116)}=5.43, \quad P<0.05\right)$, whereas no significant differences were disclosed between DA-injected U-T groups $\left(F_{(3,116)}=0.08\right.$, $P=0.78)$. Thus, the same doses of DA that previously showed a facilitatory effect on aversive memory now reveal an amnesic effect on appetitive memory.

Secondly, to confirm and expand the previous result, we wanted to disclose whether the memory impairment effect of DA is actually a consequence of an action on specific receptors. Therefore, we analyzed whether we could revert the amnesic effect of DA with a DA-receptor antagonist. The experiment included three pairs of groups: a SAL pair, injected with saline solution; a DA pair, injected with $0.1 \mathrm{mM} \mathrm{DA}$, and a group injected with a cocktail of $0.1 \mathrm{mM} \mathrm{DA}+0.1 \mathrm{mM}$ FLU (DA + FLU pair). Results corresponding to the test session are shown in Figure 7B. Planned comparisons revealed a significant difference $(\mathrm{T}>$ $\mathrm{U})$ between $\mathrm{U}-\mathrm{T}$ groups of the SAL pair $\left(F_{(1,174)}=15.20, P<\right.$ $0.001)$, as well as the DA + FLU pair $\left(F_{(1,174)}=6.30, P<0.05\right)$, but no significant differences are disclosed between DA-injected U-T groups $\left(F_{(1,174)}=0.09, P=0.77\right)$. We can conclude from this that DA amnesic effect on appetitive memory is due to the action of this amine over its specific receptors.
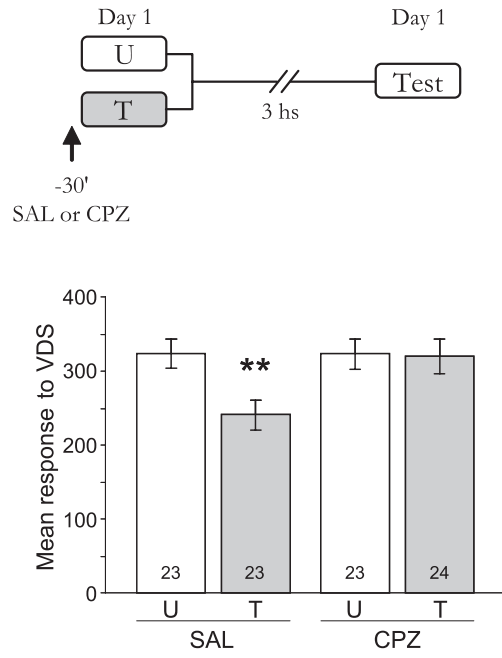

Figure 4. Amnesic effect of dopamine antagonist emerges as soon as $3 \mathrm{~h}$ after training. (Top) Experimental protocol. (Symbols as in Figure 1.) (Bottom) Escape response at testing session. Animals were systemically injected $30 \mathrm{~min}$ before training session. (Ordinates and symbols as in Figure 1.) $(* *) P<0.01$. 

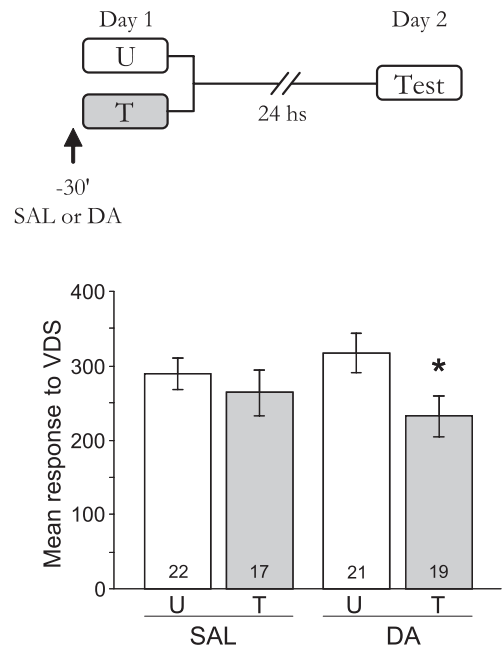

Figure 5. DA facilitates aversive memory after a weak training protocol. (Top) Experimental protocol. White box stands for $U$ groups and gray box for weak-trained (WT) groups that received five VDS presentations. Systemic injections were performed 30 min before training session (arrow). Testing session was performed $24 \mathrm{~h}$ later. (Bottom) Escape response at testing session. (Ordinates and symbols as in Figure 1.) Animals were injected with saline or $100 \mu \mathrm{M} \mathrm{DA} .\left(^{*}\right) P<0.05$.

\section{Dopaminergic immunolabeling in the brain of Chasmagnathus}

The previous results provided us motivation for localizing dopaminergic neurons in the brain of the crab Chasmagnathus granulatus. We describe the localization of cells and axons containing tyrosine hydroxilase $(\mathrm{TH})$, the key enzyme in the biosynthesis from tyrosine to DA in the central nervous system of the crab. Previous immunohistological studies in related crustaceans have shown that antibodies against dopamine and against $\mathrm{TH}$ yield highly consistent staining patterns (Cournil et al. 1994; Wood and Derby 1996) and validate the use of anti-TH as a reliable marker of dopaminergic neurons in crustaceans. The brain of decapod crustaceans consists of a protocerebrum, a deuterocerebrum, and a tritocerebrum. The protocerebrum is divided into three parts: the optic ganglia and the lateral protocerebrum, both located inside the eyestalks, and the median protocerebrum, which is anatomically part of the supraoesophageal ganglion together with the deutero- and the tritocerebrum. The optic ganglia are in turn subdivided into three neuropils: the lamina ganglionaris, the external medulla, and the internal medulla (Sandeman 1964), sequentially organized from periphery to center, which are assumed to perform visual processing with increasing degrees of integration (Sztarker et al. 2005). Interestingly, we found TH-immunoreactive neurons in all of the observed ganglia of the central nervous system that project locally and to distant targets.

In the optic ganglia (Fig. 8A,B), we found immunoreactive cell bodies in the cluster 2 located in the distal rim of the external medulla and a homogeneous staining in the region that corresponds to columnar projections of the stained somas. A high TH immunoreactivity was also found in a fraction of somas of the cluster 3 attached to the internal medulla and in the corresponding columnar neurons of the same neuropil. The TH-staining patterns in the external and internal medulla reveal several transversal layers, which presumably correspond to synaptic regions among columnar neurons, as well as with tangential neurons that collect retinotopic information (Sztarker et al. 2005). Interestingly, these neurons were previously shown to process the visual information of the aversive stimulus used in this study (Tomsic et al. 2003).

The lateral protocerebrum does not show a geometrically organized TH staining as the optic ganglia neuropils (Fig. 8A). A fraction of TH-positive somas were found in two clusters localized adjacent to the lateral protocerebrum. Some of these neurons show arborizations that vanish in thin fibers locally and produce a dotted pattern presumably related to dopaminergic terminals all over this region, while some other fibers project to the protocerebral tract toward the supraoesophageal ganglion. Adjacent to the lateral protocerebrum, the sinus gland and the X-organ, two important neurohemal glands, show intense TH-immunoreactivity (data not shown), consistent with the well-documented role of DA as a neurohormone (Christie 2011).

In the supraoesophageal ganglion, TH staining reveals a complex network of neurons that interconnect neuropils inside this ganglion and with other ganglia (Fig. 8C,D). Approximately 20 TH-positive fibers can be visualized coming from the eyestalks and connecting with the supraoesophageal ganglion. The majority of these fibers run through the protocerebral tract, while a few of them do it through the olfactory glomerular tract and the oculomotor nerve. Some fibers arborize in the central body and in the anteromedial protocerebral neuropils, and then enter the
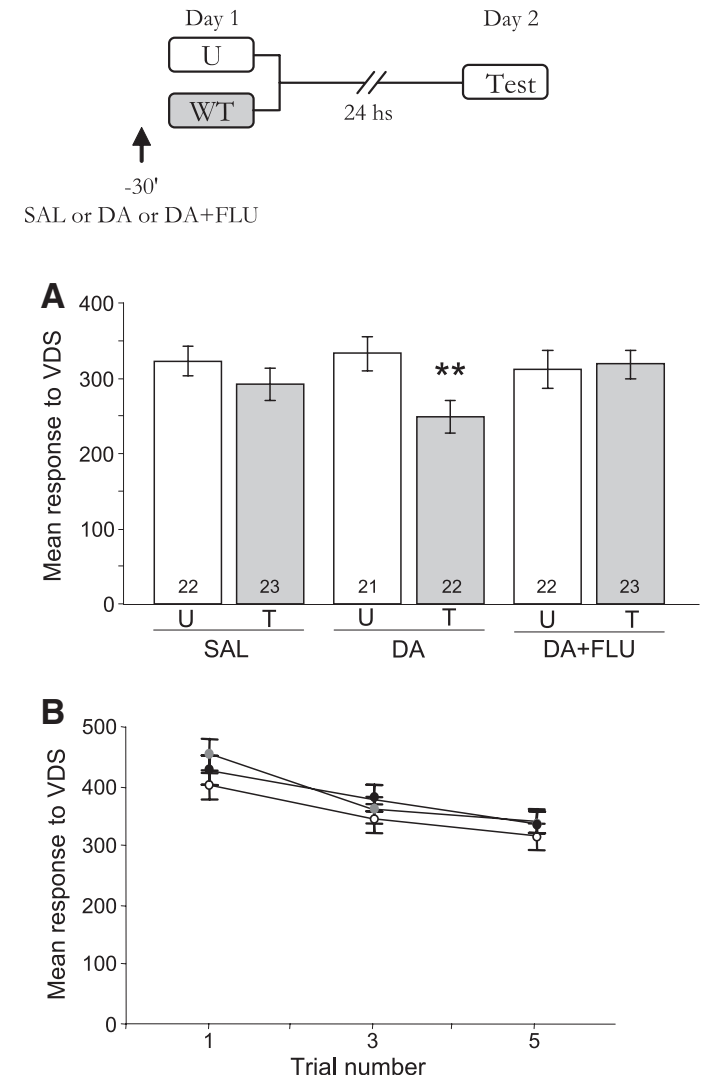

Figure 6. Dopamine antagonist blocks memory facilitation induced by dopamine. (Top) Experimental protocol. White box stands for $U$ groups and gray box for weak-trained (WT) groups. Systemic injections were performed 30 min before training session (arrow). (Bottom) (A) Fluphenazine blocks DA effect when both are coinjected. Escape response at testing session. (Ordinates and symbols as in Figure 1.) Animals were injected with saline, $100 \mu \mathrm{M}$ DA, or $100 \mu \mathrm{M} \mathrm{DA}+100 \mu \mathrm{M}$ fluphenazine. (B) DA does not improve acquisition. Escape response during training session. (Ordinates and symbols as in Figure 1.) Animals were injected with saline (black circles), $100 \mu \mathrm{M}$ DA (gray circles), or $100 \mu \mathrm{M}$ DA + $100 \mu \mathrm{M}$ fluphenazine (white circles). (**) $P<0.01$. 

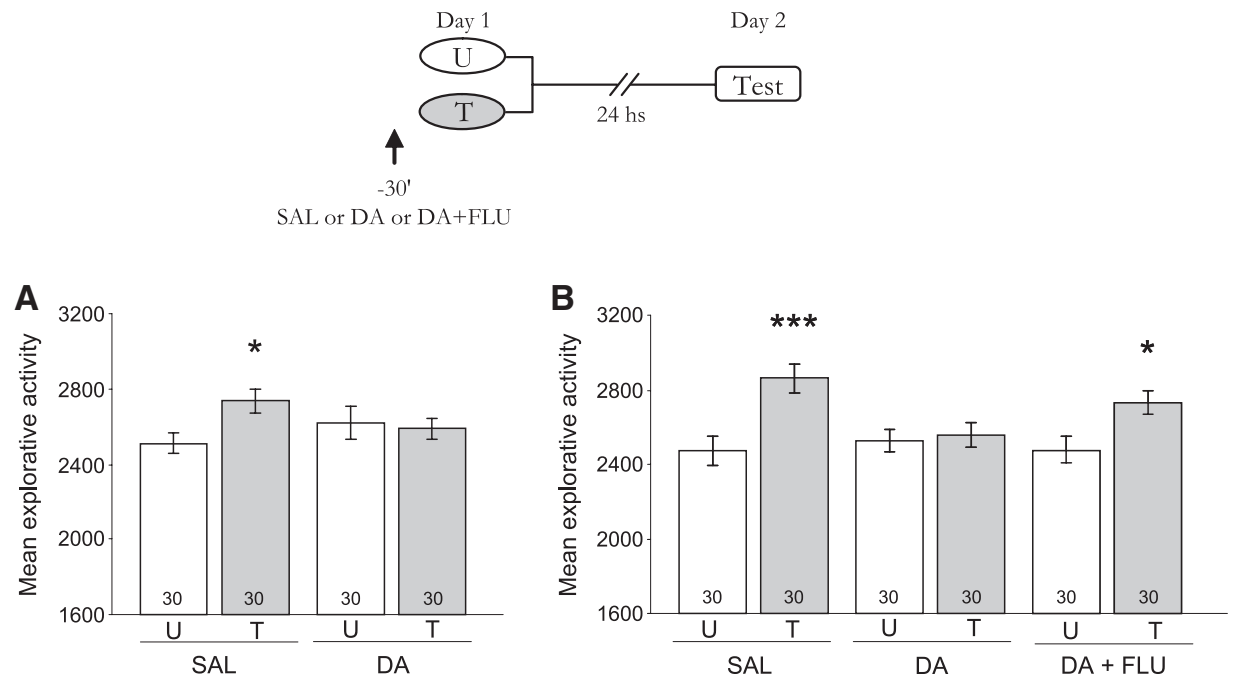

Figure 7. DA impairs appetitive memory. (Top) Experimental protocol. White oval stands for untrained groups (U), i.e., no food while being in the training context; gray oval for trained groups $(\mathrm{T})$, i.e., food pellet of $80 \mathrm{mg}$ for $30 \mathrm{~min}$. Systemic injections were performed 30 min before training session (arrow). Testing session was performed $48 \mathrm{~h}$ later. (Bottom) Explorative response at testing session. Mean response \pm S.E.M. White bars stand for untrained groups and gray bars stand for trained groups. (A) DA impairs appetitive memory. Animals were injected with saline or $100 \mu \mathrm{M}$ DA. (B) Fluphenazine blocks DA effect when both are coinjected. Animals were injected with saline, $100 \mu \mathrm{M}$ DA, or $100 \mu \mathrm{M}$ DA $+100 \mu \mathrm{M}$ fluphenazine $\left({ }^{*}\right) P<0.05,\left({ }^{* *}\right) P<0.001$

contralateral protocerebral tract. We did not find any cluster or tract in the supraoesophageal ganglion that was homogenously stained with the anti-TH antibody. In contrast, TH-positive cells are spread in several clusters with a strict bilateral distribution. Immunoreactive somas neighbor nonstained ones, revealing the neurochemical heterogeneity of all clusters. Consistent with previous reports from other crustaceans, a major fraction of TH-positive cells are located in the cluster 6 , a prominent cluster placed in the anterior margin of the supraoesophageal ganglion (Cournil et al. 1994; Fort et al. 2004). Although the projections of these neurons do not share a common arborization pattern, all of them could be traced reaching distant neuropils in the supraoesophageal ganglion. Two conspicuous TH-positive fibers entered the olfactory lobe and arborized in the neuropils. Several conspicuous TH-positive neurons were consistently recognized in all preparations and two of them matched previous descriptions performed in other crustaceans. The latter are the paired L cells whose soma and axon are recognizable in the circumoesophageal connective (Fort et al. 2004) and the paired Br cells previously described in Homarus gammarus (Beltz 1999). The Br cells show a prominent cell body located in the cluster 16 , adjacent to the olfactory lobe, and arborize bilaterally in the whole supraoesophageal ganglion, anterior and posterior neuropils, also sending projections to the circumoesophageal connective.

In summary, dopaminergic neurons are widely distributed in the brain of Chasmagnathus. While in the optic ganglia TH-positive neurons seem to be part of local arrays involved in visual processing, in the rest of the brain, dopaminergic neurons project distally, interconnecting several neuropils.

\section{Discussion}

In the present study we have analyzed the role of the dopaminergic system in the formation of aversive and appetitive memories in the crab Chasmagnathus. Our results reveal that DA has a divergent role in these two memory processes. On the one hand, we found that DA is required during aversive memory consolidation, in agreement with previous results obtained in several insect species (Schwaerzel et al. 2003; Unoki et al. 2005, 2006; Vergoz et al. 2007). On the other hand, DA treatment during training was found to impair formation of long-term appetitive memory, a function that has not been described until now. Finally, as a first step to elucidate the neuroanatomical correlates of DA action on memory, we mapped the crab's dopaminergic system. We found a prominent and wide distribution of DA-synthesizing neurons throughout the central nervous system. In particular, a distinctive dopaminergic pattern was found in the internal medulla, an area in which the visual danger stimulus (i.e., the aversive US) is initially processed (Tomsic et al. 2003), suggesting that they might be involved in memory formation.

\section{Dopamine is required for a contextual aversive memory formation}

Firstly, we addressed the involvement of the dopaminergic system in aversive memory formation by blocking DA receptors. We found that three different DA-receptor antagonists (chlorpromazine, fluphenazine, and SCH23390) impair aversive memory, when applied $30 \mathrm{~min}$ before training (Fig. 1), without affecting the animal's acquisition (Fig. 2). Although the specificity of all of these drugs has not been tested in crabs, the fact that three distinct DA-receptor antagonists similarly impaired aversive memory indicates that the observed effects are a consequence of the blockade of DA receptors. Thus, DA receptors do, indeed, play a fundamental role on this mnemonic process. Interestingly, we found a very narrow time interval of DA requirement during memory formation. That is, the DA-receptor antagonist fluphenazine impairs memory retention only when applied $30 \mathrm{~min}$ before training (Fig. 3) and its amnesic effect is already observed $3 \mathrm{~h}$ after training (Fig. 4). It is possible that the injections applied outside of this time interval do not provide an optimal drug concentration during the critical period in which DA is required for memory formation. The time window of efficacy of DA-receptor antagonists that we report in this work is very similar to the one reported in other learning paradigms in insects (Unoki et al. 2005, 2006; Vergoz et al. 2007), which supports the idea of a common mechanism of action of DA across different species and memory models. 

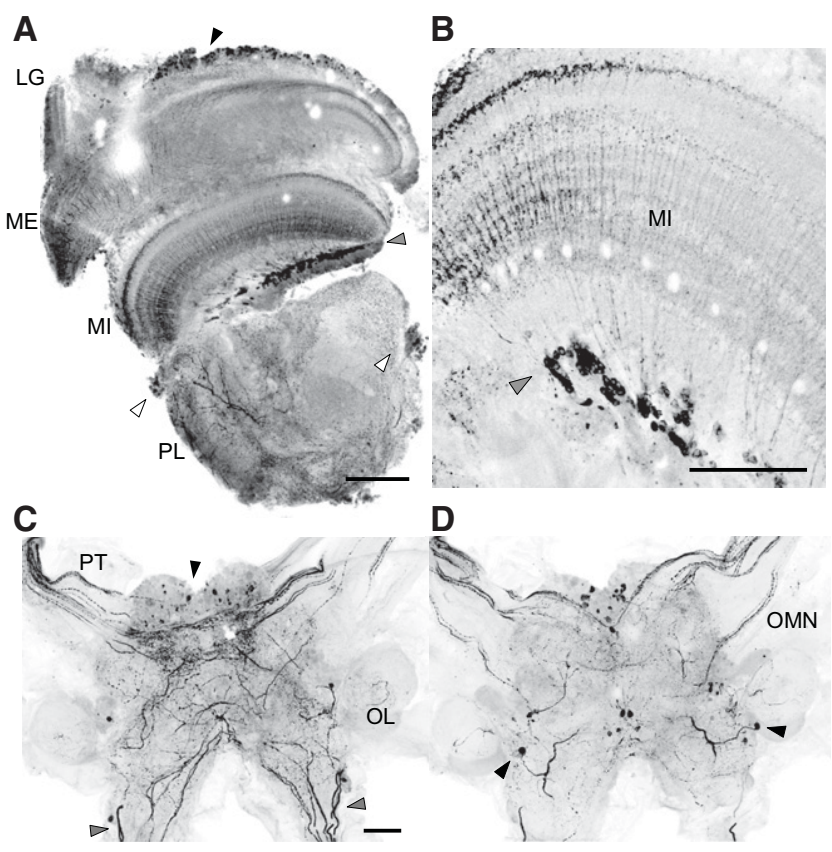

Figure 8. TH labeling of the central nervous system of Chasmagnathus granulatus. $(A)$ Optic ganglia and lateral protocerebrum. Immunoreactive cell bodies in the cluster 2 located in the distal rim of the external medulla (black arrowhead). Immunoreactive somas of the cluster 3 located in the proximal part of the MI (gray arrowhead). TH-positive somas in two clusters adjacent to PL (white arrowheads). Scale bar, $100 \mu \mathrm{m}$. (LG) Lamina ganglionaris; (ME) external medulla; (MI) internal medulla; (PL) lateral protocerebrum. (B) Internal medulla. Immunoreactive fibers shows a columnar staining pattern and reveal tangential layers in the Ml. Scale bar, $50 \mu \mathrm{m}$. (C) Supraesophageal ganglion (dorsal view). TH labeling in cluster 6 (black arrowhead), L-cells (gray arrowhead). (PT) Protocerebral tract; (OL) olfactory lobe. (D) Supraesophageal ganglion (ventral view). $\mathrm{TH}$ labeling in $\mathrm{Br}$ cells (black arrowheads). (OMN) Oculomotor nerve. Scale bar in $C$ and $D, 100 \mu \mathrm{m}$.

While a number of studies reported a key role of the dopaminergic system in aversive memory by means of blocking DA receptors (Unoki et al. 2005, 2006; Vergoz et al. 2007), until now, no studies have directly analyzed the effect of DA as an agonist on this process. Here, we show that exogenous DA facilitates a weak aversive memory when administered before training (Fig. 5). The effect of DA is blocked when the amine is coinjected with its antagonist fluphenazine (Fig. 6A), providing additional evidence of the specific action of both drugs. Thus, these results demonstrate that a weak memory can be strengthened by increasing DA levels. We suggest that exogenous DA combines with the internal dopaminergic signal induced by the weak training protocol, emulating the effects of a stronger protocol, making it possible to establish a long-term memory.

Interestingly, identical results to the ones obtained in the present work with DA and DA-receptor antagonists have been reported in previous studies in this crab using PKA activators and inhibitors, respectively (Romano et al. 1996; Locatelli et al. 2002; Locatelli and Romano 2005). Pharmacological activation of PKA during learning was found to improve long-term memory formation after a weak training protocol, while inhibition of PKA during learning impaired long-term memory measured $24 \mathrm{~h}$ after a strong training protocol. In addition, the limited time window of efficacy of the drugs that act on the cAMP-PKA pathway coincides with the one obtained in the present study with the pharmacological treatments that affect the dopaminergic pathway. Remarkably, several DA-receptor subtypes were recently sequenced and characterized in the lobster Panulirus interruptus, confirming that dopaminergic transmission in crustaceans is transduced by G-protein-coupled receptors that modify cAMP levels in the cells (Clark and Baro 2006, 2007).

From our results and the above-mentioned studies, we suggest that DA conveys at least a component of the aversive signal in the crab's nervous system that is transduced by the cAMPPKA pathway, and allows animals to form an associative aversive memory, i.e., the context-VDS memory.

\section{Dopamine impairs an appetitive memory}

A recent report based on the appetitive and the aversive memory paradigms in the crab showed that octopamine (OA) plays contrasting roles in appetitive and aversive memories: While octopaminergic signaling is required for appetitive memory formation, it has a deleterious effect on aversive memory consolidation (Kaczer and Maldonado 2009). We further hypothesized that DA may also play such a dual role, but symmetric to the one of octopamine. In this sense, previous works in insects have described a dopaminergic modulation appetitive memory. A seminal work by Mercer and Menzel (1982) reported that injection of DA impairs retrieval of appetitive memory in honey bees. Along the same line, a more recent study by Krashes et al. (2009) revealed a set of dopaminergic neurons that controls the retrieval of appetitive memory in Drosophila. Both studies indicate that DA hinders expression of appetitive memory, but not its acquisition or storage. In contrast to these results, the studies by Selcho et al. (2009) and Kim et al. (2007) showed that a dopaminergic component is actually needed for appetitive learning and memory.

In the present study we found that DA impairs long-term appetitive memory when injected $30 \mathrm{~min}$ before training (Fig. 7A), and that this effect is blocked by a coinjection with a DA-receptor antagonist (Fig. 7B). DA administration did not affect the crab's exploratory activity or feeding behavior, thus suggesting that the amine's effect is not due to impairment of the crab's motivational state. Furthermore, since there is a 2-d interval between the time of DA administration and the time of the testing session, and also considering that the half-life of DA was shown to be in the order of minutes in a related crab species (Hoeger and Florey 1989), it is very unlikely that DA has affected appetitive memory by interfering during retrieval. Also, several studies in insects found that injections of DA are effective $\sim 30 \mathrm{~min}$ after drug application, and its effect vanishes $1 \mathrm{~h}$ after injection (Menzel et al. 1990; Scheiner et al. 2002). Thus, we propose that the most reasonable explanation for our results is that DA interferes with appetitive memory formation during an early stage of the consolidation process. However, we cannot rule out that retrieval could also be modulated by DA if the injection time occurred close to the testing session.

\section{Dopaminergic system in the brain of Chasmagnathus}

Behavioral and pharmacological results of the present study provide an insight into how two different memory processes can be differentially modulated by DA. From this, it is suggested that DA is involved in the circuitry related to formation of aversive and appetitive memories. This motivated us to localize DA-synthesizing neurons in the central brain of the crab Chasmagnathus, which could provide neuroanatomical support for the effects of DA on memory.

The distribution of DA in the nervous system has been mapped in a number of crustacean species (Cournil et al. 1994; Schmidt and Ache 1994; Wood and Derby 1996; Schmidt 1997; Tierney et al. 2003). These studies indicate that DA-containing neurons occur in all ganglia of the central nervous system with a widespread distribution and extensive processes. From the architecture of the dopaminergic system, it was suggested that DA 
could play an important role in modulating neural activity and in coordinating neural circuits (Tierney et al. 2003). In agreement with other crustacean species, we found dopaminergic neurons all across the central brain of Chasmagnathus (Fig. 8C,D). TH-stained neurons project distally and interconnect several neuropils of the supraoesophageal ganglia. This pattern would be consistent with a role of DA acting as a neurotransmitter of multisensory and integrative pathways. Interestingly, a series of studies have indicated that the central complex, a prominent structure in the central brain of insects, is involved in visual pattern memory (Liu et al. 2006; Pan et al. 2009) and spatial orientation memory (Neuser et al. 2008). Considering that a possible homology has been suggested between the central body of crustaceans and that of insects (Utting et al. 2000), and that we found a number of dopaminergic fibers connecting the optic neuropils with the central body, it would be interesting to analyze the role of this area in the formation of the aversive visual memory.

In addition, we found a conspicuous pattern of putative dopaminergic neurons in the optic ganglia of Chasmagnathus (Fig. $8 \mathrm{~A}, \mathrm{~B})$ that is consistent with a previous report in the crayfish visual system (Wood and Derby 1996). TH-positive neurons are homogenously distributed across different neuropils of the optic ganglia, which consist of a retinotopic array of columnar projection neurons (Sztarker et al. 2005). The distribution of the staining suggests that dopaminergic neurons could be an intrinsic part of neural arrays involved in local processing of visual information. Interestingly, it has been shown in Chasmagnathus that tangential neurons that collect information from the columnar elements in the optic neuropils respond to moving objects and show longlasting plasticity upon iterative presentation of the same visual danger stimuli that we used in the present study (Tomsic et al. 2003). From this and our present results, we suggest that the action of the dopaminergic neurons in the optic ganglia might be involved in the plasticity of the motion-sensitive neurons and the formation of the aversive visual memory.

\section{Dual role of biogenic amines in appetitive and aversive memories}

Taking together the results of the present study about DA action in aversive and appetitive memories in the crab, and a previous one about the role of $\mathrm{OA}$ in these processes (Kaczer and Maldonado 2009), we find that these amines mirror each other in their actions.

We propose that each biogenic amine (OA and DA) has a dual action on memory processes: on the one hand, they mediate the appetitive and the aversive signal throughout training, instructing the nervous system about the value of the unconditioned stimulus (Giurfa 2006), while on the other hand, they interfere with the opposite learning. The results of the present study indicate that endogenous DA would accomplish the instructive function during aversive memory formation, and previous data suggested that OA would have a similar function in appetitive memory. In addition, it was demonstrated that both amines have a detrimental effect on the memories of opposite sign (Kaczer and Maldonado 2009; this work). Thus, we propose that the DA-ergic and OA-ergic systems should not work disjointedly, but interact in a coordinated manner during memory formation to provide adaptive behavior and avoid conflicting behavioral outputs. A neuroanatomical basis for this interaction is becoming comprehensible after several studies started mapping and measuring the dopaminergic and octopaminergic inputs into the mushroom bodies in Drosophila (for review, see Waddell 2010).

Finally, it is interesting to discuss how the nervous system labels as "appetitive" or "aversive" a certain stimulus or experience. Is it a binomial categorization, or is it a continuum of different hedonic values ranging from purely appetitive to purely aversive? We think that pure appetitive or aversive experiences do not exist in nature. Instead, actions or stimuli are linked to a number of concurrent appetitive and aversive consequences. Thus, the categorization of a conditioned stimulus as predictor of an appetitive or aversive consequence must arise from the balance reached by both competing components. In line with this interpretation, a recent work performed in honey bees showed that at least part of the aversive component that reduces the acquisition of the appetitive response during conditioned taste aversion is mediated by DA (Wright et al. 2010). We provide here and in a previous work (Kaczer and Maldonado 2009) evidence of the competition between appetitive and aversive signals during memory formation in the crab Chasmagnathus. According to our results, the appetitive and aversive pathways are mediated by OA and DA, respectively. These amines are not only involved in appetitive and aversive memory formation, but also exert a detrimental action on memories of the opposite sign.

\section{Materials and Methods}

\section{Animals}

Intermolt adult male Chasmagnathus granulatus (Decapoda, Brachyura, currently also designated Neohelice granulata) crabs, $2.7-3.0 \mathrm{~cm}$ across the carapace, weighing around $17.0 \mathrm{~g}$, were collected from water $<1 \mathrm{~m}$ deep in the narrow coastal inlets of San Clemente del Tuyú, Argentina, from December to August (excluding the reproductive season). In the laboratory, crabs were maintained on a 12:12 h light:dark cycle, in collective tanks (20 animals each) filled to a depth of $2 \mathrm{~cm}$ with $12 \%$ artificial seawater prepared with hw-Marinex (Winex, Germany) salt ( $\mathrm{pH}$ 7.4-7.6). The holding and the experimental rooms were both maintained between 22 and $24^{\circ} \mathrm{C}$. Experiments were carried out within the first week after the animals' arrival. Each crab was used only in one experiment. Experiments were carried out in accordance with the National Institute of Health Guide for the Care and Use of Laboratory Animals (NIH publication 80-23/96), USA, and with local regulations.

\section{Experimental design}

Each experiment included two sessions: training and testing, performed on different days. In each experiment, pairs of groups were formed and each pair included one trained $(\mathrm{T})$ group that received the US during the training session, and one untrained (U) group that stayed in the training context during the whole session without receiving the US. Immediately after the training session, crabs were removed from the training arena to be housed individually in resting containers, i.e., plastic cylinders covered to a depth of $0.8 \mathrm{~cm}$ with water, and kept inside dimly lit drawers.

The training context consisted of a bowl-shaped opaque container with a steep concave wall $12-\mathrm{cm}$ high $(23 \mathrm{~cm}$ top diameter and $9 \mathrm{~cm}$ floor diameter) covered to a depth of $0.5 \mathrm{~cm}$ with artificial sea water, where the crab was lodged during each experiment. The setup is illuminated from above by a 10W lamp. The appetitive and the aversive paradigms had the same training context.

Exploratory and escape behavior were obtained from the total distance covered by each crab during each experimental session, measured by means of video motion tracking $(2 \mathrm{~Hz})$, expressed in arbitrary units. Each crab was marked with a dot of yellow paint in the center of the cephalothorax the day before the experiment and then video recorded at training and testing. Custom-designed software determined the coordinates of the yellow spot at each time point, which allowed us to track animal's position and obtain a numeric value for the total distance explored or escaped by each crab.

\section{Aversive paradigm}

\section{Training}

A training trial consisted of presenting an opaque square figure of $4 \times 4 \mathrm{~cm}$, the visual danger stimulus (VDS), operated by a motor. 
The figure moved downward and upward (Lozada et al. 1990) twice, first closely approaching the animal (without touching it) and then moving away up to the initial position, during 9 sec. Two types of training protocols were used. The strong training protocol consisted of 15 presentations of the VDS and the weak training consisted of five VDS presentations; in both cases, the trials were separated by 3-min intervals. The initial response to this aversive stimulus was to escape from the VDS, and this response declines upon repetitive VDS presentations (Lozada et al. 1990).

\section{Testing}

Crabs were tested $24 \mathrm{~h}$ after training. They were placed again in the training context and received one VDS presentation (test trial) after a 5-min adaptation period. The change in the response was a reduction in the level of escape evoked by the VDS (Pereyra et al. 2000).

\section{Memory}

A trained (T) group is said to show memory retention when its mean response level at test trial is statistically lower than that of the respective untrained $(\mathrm{U})$ group.

\section{Appetitive paradigm}

\section{Training}

Animals were placed in the training context, and after 5 min they received a food pellet of $80 \mathrm{mg}$ (rabbit-chow, Nutrientes S.A.), left for $30 \mathrm{~min}$. The initial response to the appetitive stimulus was to explore the container before its first contact with food. Once the animals found the pellet, they consumed it immediately, breaking it into pieces with their chelae.

\section{Testing}

Crabs were tested $48 \mathrm{~h}$ after training. They were placed again in the training context and stayed there for $5 \mathrm{~min}$. The conditioned response was a more intensive context exploration (Kaczer and Maldonado 2009).

\section{Memory}

A trained (T) group is said to show memory retention when its mean explored distance is statistically greater than the respective untrained (U) group.

\section{Data analysis}

Memory retention was assessed, focusing data analysis on test trial scores, by estimating the difference between the T group and the respective U group of each pair. Rescorla (1988) convincingly argued in favor of using this sort of analysis instead of a paired training-testing comparison, stressing the need to clearly distinguish between time of input (training session) and time of assessment (testing session). A basic prediction of our analysis is that in both aversive and appetitive paradigms a significant U-T difference is invariably disclosed at the test session. Based on this prediction, results in all cases were analyzed with a priori planned comparisons LSD using a weighted means ANOVA with $\alpha=0.05$ (per comparison error rate), according to the standard method (Rosenthal and Rosnow 1985; Howell 1987). In every experiment the following contrasts were carried out: between each $U$ group and its respective $\mathrm{T}$ group, to evaluate memory retention, and between $U$ groups, to analyze any unspecific drug effect. No significant difference between U groups was disclosed throughout this study. A significant U-T difference is the operative definition of "memory retention;" while a nonsignificant U-T difference is an operative definition of "memory impairment" resulting from a treatment or experimental factor.

\section{Drugs and injection procedure}

Crustacean saline solution (in molar concentrations: $\mathrm{NaCl} 0.45$, $\mathrm{CaCl}_{2} 0.015, \mathrm{MgCl}_{2} 0.021, \mathrm{KCl} \mathrm{0.01)}$ was used as a vehicle. Fifty microliters of saline or drug solution were injected through the right side of the dorsal cephalothoraxic-abdominal membrane by means of a syringe fitted with a sleeve to control the depth of penetration to $4 \mathrm{~mm}$, thus ensuring that the injected solution was released in the pericardial sac. The lack of an endothelial blood-brain barrier in crabs (Abbott 1970) together with the fact that blood is distributed throughout an extensive capillary system (Sandeman 1967) makes it possible for the injected drugs to reach the neuropil areas of the brain. Drug solutions were prepared to inject: Dopamine $0.1 \mathrm{mM}$; Fluphenazine $1 \mathrm{mM}$, Chlorpromazine $1 \mathrm{mM}$, and SCH23390 $1 \mathrm{mM}$. Final drug concentrations in hemolymph were estimated as 1:100-fold diluted, considering that the hemolymph volume is $\sim 5 \mathrm{~mL}$ (Gleeson and Zubkoff 1977). All drugs were purchased from Sigma Aldrich.

\section{Immunohistochemistry}

Animals were cooled in ice-water for $10 \mathrm{~min}$ before dissection. Supraoesophageal and optic lobes were dissected in 4\% paraformaldehyde and fixated for $2 \mathrm{~h}$ at room temperature. The following steps were performed at $4^{\circ} \mathrm{C}$ under gentle shaking. After fixation, ganglia were washed in PBS $(2 \times 30 \mathrm{~min})$ and permeabilized by a dehydration sequence of 10 -min steps in $50 \%, 70 \%$, $90 \%, 96 \%$, and $100 \%$ ethanol, and rehydration back to distilled water. The ganglia were rinsed in PBS $(2 \times 30 \mathrm{~min})$ and blocked overnight in PBS $0.01 \mathrm{M}$, BSA $2 \%$, and TritonX100 0.1\%, NGS $5 \%$. After blocking, ganglia were washed in PBS $(2 \times 30 \mathrm{~min})$ and incubated for $72 \mathrm{~h}$ with anti-Tyrosine hydroxylase antibody (Ab152: Chemicon) diluted $1 / 50$ in PBS $0.01 \mathrm{M}$, Tween $0.3 \%$, NGS $1 \%$ preserved with sodium azide. The first antibody was removed and the ganglia washed $(3 \times 2 \mathrm{~h})$ in PBS $0.01 \mathrm{M}$ and further incubated with an Alexa Fluor 488-labeled goat anti rabbit antibody (Invitrogen A11008) 1/500 in PBS $0.01 \mathrm{M}$ for $48 \mathrm{~h}$. The secondary antibody was removed and the ganglia were washed three times for $30 \mathrm{~min}$, plus one wash overnight in PBS, Tween $0.3 \%$. Samples were finally dehydrated in 50\%, 70\%, 90\%, 96\%, and $100 \%$ ethanol steps, $10 \mathrm{~min}$ each, and whole mounted in metylsalicylate. All ganglia were viewed using a confocal microscope Olympus FV300 and a 488nM Argon laser. Optic slices were $1-\mu \mathrm{m}$ thick. Control procedures omitting the first antibody did not show any staining.

\section{Acknowledgments}

This work is dedicated to the memory of our mentor Hector Maldonado, who conceived most of the ideas that inspired this study. We thank Arturo Romano, Martín Berón de Astrada, and Yanil Hepp for their helpful suggestions on this manuscript, and Angel Vidal for technical assistance. This work was supported by the Argentinean ANPCYT (grant PICT 02261) and CONICET (grant 112-200801-02457). L.K. is supported by a Bunge y Born Postdoctoral fellowship.

\section{References}

Abbott J. 1970. Absence of blood-brain barrier in a crustacean, Carcinus maenas L. Nature 225: 291-293.

Agarwal M, Giannoni Guzmán M, Morales-Matos C, Del Valle Díaz RA, Abramson CI, Giray T. 2011. Dopamine and octopamine influence avoidance learning of honey bees in a place preference assay. PLoS One 69: e25371. doi: 10.1371/journal.pone.0025371.

Aso Y, Siwanowicz I, Bracker L, Ito K, Kitamoto T, Tanimoto H. 2010. Specific dopaminergic neurons for the formation of labile aversive memory. Curr Biol 20: $1445-1451$.

Beltz BS. 1999. Distribution and functional anatomy of amine-containing neurons in decapod crustaceans. Microsc Res Tech 44: 105-120.

Blenau W, Erber J, Baumann A. 1998. Characterization of a dopamine D1 receptor from Apis mellifera: Cloning, functional expression, pharmacology, and mRNA localization in the brain. J Neurochem 70: $15-23$.

Christie AE. 2011. Crustacean neuroendocrine systems and their signaling agents. Cell Tissue Res 345: 41-67.

Claridge-Chang A, Roorda RD, Vrontou E, Sjulson L, Li H, Hirsh J, Miesenbock G. 2009. Writing memories with light-addressable reinforcement circuitry. Cell 139: $405-415$. 
Clark MC, Baro DJ. 2006. Molecular cloning and characterization of crustacean type-one dopamine receptors: D1 $\alpha$ Pan and D1 Pan. Comp Biochem Physiol B Biochem Mol Biol 143: 294-301.

Clark MC, Baro DJ. 2007. Arthropod D2 receptors positively couple with cAMP through the Gi/o protein family. Comp Biochem Physiol B Biochem Mol Biol 146: 9-19.

Cournil I, Helluy SM, Beltz BS. 1994. Dopamine in the lobster Homarus gammarus. I. Comparative analysis of dopamine and tyrosine hydroxylase immunoreactivities in the nervous system of the juvenile. J Comp Neurol 344: 455-469.

Degen J, Gewecke M, Roeder T. 2000. Octopamine receptors in the honey bee and locust nervous system: Pharmacological similarities between homologous receptors of distantly related species. Br J Pharmacol 130: 587-594.

Delorenzi A, Dimant B, Frenkel L, Nahmod VE, Nassel DR, Maldonado H. 2000. High environmental salinity induces memory enhancement and increases levels of brain angiotensin-like peptides in the crab Chasmagnathus granulatus. J Exp Biol 203: 3369-3379.

Farooqui T, Robinson K, Vaessin H, Smith B. 2003. Modulation of early olfactory processing by an octopaminergic reinforcement pathway in the honeybee. J Neurosci 23: 5370-5380.

Fort TJ, Brezina V, Miller MW. 2004. Modulation of an integrated central pattern generator-effector system: Dopaminergic regulation of cardiac activity in the blue crab Callinectes sapidus. J Neurophysiol 92: $3455-3470$

Giurfa M. 2006. Associative learning: The instructive function of biogenic amines. Curr Biol 16: R892-R895.

Gleeson R, Zubkoff P. 1977. The determination of hemolymph volume in the blue crab, Callinectes sapidus, utilizing 14C-thiocyanate. Comp Biochem Physiol 56A: 411-413.

Hammer M, Menzel R. 1998. Multiple sites of associative odor learning as revealed by local brain microinjections of octopamine in honeybees. Learn Mem 5: 146-156.

Heisenberg M. 2003. Mushroom body memoir: From maps to models. Nat Rev Neurosci 4: $266-275$.

Hermitte G, Pedreira ME, Tomsic D, Maldonado H. 1999. Context shift and protein synthesis inhibition disrupt long-term habituation after spaced, but not massed, training in the crab Chasmagnathus. Neurobiol Learn Mem 71: 34-49.

Hoeger U, Florey E. 1989. Catecholamine degradation in the hemolymph of the Chinese crab, Eriocher Sinensis. Comp Biochem Physio C 92: 323-327.

Honjo K, Furukubo-Tokunaga K. 2009. Distinctive neuronal networks and biochemical pathways for appetitive and aversive memory in Drosophila larvae. J Neurosci 29: 852-862.

Howell DC. 1987. Statistical methods for psychology. PWS-Kent Publishing, Boston, MA.

Kaczer L, Maldonado H. 2009. Contrasting role of octopamine in appetitive and aversive learning in the crab Chasmagnathus. PLoS One 4: e6223. doi: 10.1371 /journal.pone.0006223.

Kaczer L, Klappenbach M, Maldonado H. 2011. Dissecting mechanisms of reconsolidation: Octopamine reveals differences between appetitive and aversive memories in the crab Chasmagnathus. Eur J Neurosci 34 $1170-1178$.

Kim YC, Lee HG, Han KA. 2007. D1 dopamine receptor dDA1 is required in the mushroom body neurons for aversive and appetitive learning in Drosophila. J Neurosci 27: 7640-7647.

Krashes MJ, DasGupta S, Vreede A, White B, Armstrong JD, Waddell S. 2009. A neural circuit mechanism integrating motivational state with memory expression in Drosophila. Cell 139: 416-427.

Liu G, Seiler H, Wen A, Zars T, Ito K, Wolf R, Heisenberg M, Liu L. 2006. Distinct memory traces for two visual features in the Drosophila brain. Nature 439: 551-556.

Locatelli F, Romano A. 2005. Differential activity profile of cAMP-dependent protein kinase isoforms during long-term memory consolidation in the crab Chasmagnathus. Neurobiol Learn Mem 83: $232-242$.

Locatelli F, Maldonado H, Romano A. 2002. Two critical periods for cAMPdependent protein kinase activity during long-term memory consolidation in the crab Chasmagnathus. Neurobiol Learn Mem 77: 234-249.

Lozada M, Romano A, Maldonado H. 1990. Long-term habituation to a danger stimulus in the crab Chasmagnathus granulatus. Physiol Behav 47: $35-41$.

Maldonado H. 2002. Crustacean as model to investigate memory illustrated by extensive behavioral and physiological studies in Chasmagnathus. In The crustacean nervous system (ed. K Wiese), pp. 314-327. Springer, Berlin, Germany.

Menzel R, Wittstock S, Sugawa M. 1990. Chemical codes of learning and memory in honey bees. In The biology of memory (ed. L Squire, E Lindenlaub), pp. 335-355. FK Schattauer Verlag, Stuttgart-New York.

Menzel R, Leboulle G, Eisenhardt D. 2006. Small brains, bright minds. Cell 124: $237-239$
Mercer AR, Menzel R. 1982. The effect of biogenic amines on conditioned and unconditioned responses to olfactory stimuli in the honeybee Apis mellifera. J Comp Physiol 145: 363-368.

Mustard JA, Blenau W, Hamilton IS, Ward VK, Ebert PR, Mercer AR. 2003. Analysis of two D1-like dopamine receptors from the honey bee Apis mellifera reveals agonist-independent activity. Brain Res Mol Brain Res 113: $67-77$.

Neuser K, Triphan T, Mronz M, Poeck B, Strauss R. 2008. Analysis of a spatial orientation memory in Drosophila. Nature 453: 1244-1247.

Pan Y, Zhou Y, Guo C, Gong H, Gong Z, Liu L. 2009. Differential roles of the fan-shaped body and the ellipsoid body in Drosophila visual pattern memory. Learn Mem 16: 289-295.

Pedreira ME, Maldonado H. 2003. Protein synthesis subserves reconsolidation or extinction depending on reminder duration. Neuron 38: $863-869$.

Pedreira ME, Pérez-Cuesta LM, Maldonado H. 2002. Reactivation and reconsolidation of long-term memory in the crab Chasmagnathus: Protein synthesis requirement and mediation by NMDA-type glutamatergic receptors. J Neurosci 22: 8305-8311.

Pedreira ME, Pérez-Cuesta LM, Maldonado H. 2004. Mismatch between what is expected and what actually occurs triggers memory reconsolidation or extinction. Learn Mem 11: 579-585.

Pereyra P, Gonzalez Portino E, Maldonado H. 2000. Long-lasting and context-specific freezing preference is acquired after spaced repeated presentations of a danger stimulus in the crab Chasmagnathus. Neurobiol Learn Mem 74: 119-134.

Rescorla RA. 1988. Pavlovian conditioning. It's not what you think it is. Am Psychol 43: 151-160.

Riemensperger T, Voller T, Stock P, Buchner E, Fiala A. 2005. Punishment prediction by dopaminergic neurons in Drosophila. Curr Biol 15: 1953-1960.

Romano A, Locatelli F, Delorenzi A, Pedreira ME, Maldonado H. 1996. Effects of activation and inhibition of cAMP-dependent protein kinase on long-term habituation in the crab Chasmagnathus. Brain Res 735: $131-140$.

Rosenthal R, Rosnow R. 1985. Contrast analysis focused comparisons in the analysis of variance. Cambridge University Press, Cambridge, UK.

Sandeman DC. 1964. Functional distinction between oculomotor and optic nerves in Carcinus (Crustacea). Nature 201: 302-303.

Sandeman DC. 1967. The vascular circulation in the brain, optic lobes and thoracic ganglia of the crab Carcinus. Proc R Soc Lond B Biol Sci 168: $82-90$.

Scheiner R, Pluckhahn S, Oney B, Blenau W, Erber J. 2002. Behavioural pharmacology of octopamine, tyramine and dopamine in honey bees. Behav Brain Res 136: 545-553.

Schmidt M. 1997. Distribution of centrifugal neurons targeting the soma clusters of the olfactory midbrain among decapod crustaceans. Brain Res 752: $15-25$.

Schmidt M, Ache BW. 1994. Descending neurons with dopamine-like lor with substance P/FMRFamide-like immunoreactivity target the somata of olfactory interneurons in the brain of the spiny lobster, Panulirus argus. Cell Tissue Res 278: 337-352.

Schroll C, Riemensperger T, Bucher D, Ehmer J, Voller T, Erbguth K, Gerber B, Hendel T, Nagel G, Buchner E, et al. 2006. Light-induced activation of distinct modulatory neurons triggers appetitive or aversive learning in Drosophila larvae. Curr Biol 16: $1741-1747$

Schwaerzel M, Monastirioti M, Scholz H, Friggi-Grelin F, Birman S, Heisenberg M. 2003. Dopamine and octopamine differentiate between aversive and appetitive olfactory memories in Drosophila. J Neurosci $\mathbf{2 3}$ : 10495-10502.

Selcho M, Pauls D, Han KA, Stocker RF, Thum AS. 2009. The role of dopamine in Drosophila larval classical olfactory conditioning. PLoS One 4: e5897. doi: 10.1371/journal.pone.0005897.

Sztarker J, Strausfeld NJ, Tomsic D. 2005. Organization of optic lobes that support motion detection in a semiterrestrial crab. J Comp Neurol 493: 396-411.

Tierney AJ, Kim T, Abrams R. 2003. Dopamine in crayfish and other crustaceans: Distribution in the central nervous system and physiological functions. Microsc Res Tech 60: 325-335.

Tomchik SM, Davis RL. 2009. Dynamics of learning-related cAMP signaling and stimulus integration in the Drosophila olfactory pathway. Neuron 64: $510-521$.

Tomsic D, Pedreira ME, Romano A, Hermitte G, Maldonado H. 1998. Association to context as a determinant of long-term habituation in the crab Chasmagnathus. Anim Learn Behav 26: 196-209.

Tomsic D, Beron de Astrada M, Sztarker J. 2003. Identification of individual neurons reflecting short- and long-term visual memory in an arthropodo. J Neurosci 23: 8539-8546.

Unoki S, Matsumoto Y, Mizunami M. 2005. Participation of octopaminergic reward system and dopaminergic punishment system 
in insect olfactory learning revealed by pharmacological study. Eur J Neurosci 22: 1409-1416.

Unoki S, Matsumoto Y, Mizunami M. 2006. Roles of octopaminergic and dopaminergic neurons in mediating reward and punishment signals in insect visual learning. Eur J Neurosci 24: 2031-2038.

Utting M, Agricola H, Sandeman R, Sandeman D. 2000. Central complex in the brain of crayfish and its possible homology with that of insects. $J$ Comp Neurol 416: 245-261.

Vergoz V, Roussel E, Sandoz JC, Giurfa M. 2007. Aversive learning in honeybees revealed by the olfactory conditioning of the sting extension reflex. PLoS One 2: e288. doi: 10.1371/ journal.pone.0000288.
Waddell S. 2010. Dopamine reveals neural circuit mechanisms of fly memory. Trends Neurosci 33: 457-464.

Wood DE, Derby CD. 1996. Distribution of dopamine-like immunoreactivity suggests a role for dopamine in the courtship display behavior of the blue crab, Callinectes sapidus. Cell Tissue Res 285: 321-330.

Wright GA, Mustard JA, Simcock NK, Ross-Taylor AA, McNicholas LD Popescu A, Marion-Poll F. 2010. Parallel reinforcement pathways for conditioned food aversions in the honeybee. Curr Biol 20: 2234-2240.

Received October 6, 2011; accepted in revised form October 15, 2011. 


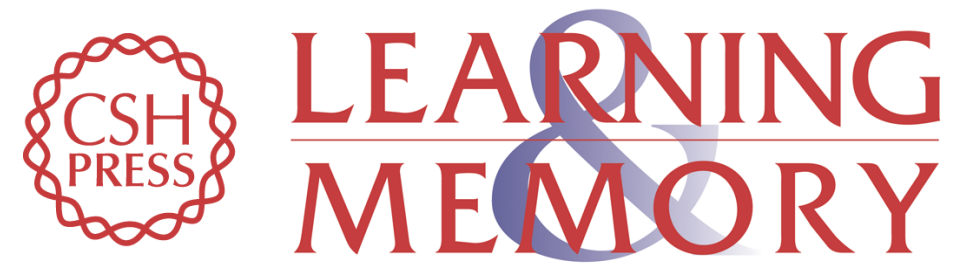

\section{Opposite actions of dopamine on aversive and appetitive memories in the crab}

Martín Klappenbach, Héctor Maldonado, Fernando Locatelli, et al.

Learn. Mem. 2012, 19:

Access the most recent version at doi:10.1101//m.024430.111

References This article cites 61 articles, 10 of which can be accessed free at: http://learnmem.cshlp.org/content/19/2/73.full.html\#ref-list-1

License

Email Alerting Receive free email alerts when new articles cite this article - sign up in the box at the Service top right corner of the article or click here. 